\title{
Introduction to the Minitrack on Digital Innovation
}

\author{
Nicholas Berente \\ University of Georgia \\ berente@uga.edu
}

\author{
Kalle Lyytinen \\ Case Western Reserve \\ University \\ kalle@,case.edu
}

\author{
Youngjin Yoo \\ Case Western Reserve \\ University \\ youngjin.yoo@case.edu
}

Organizations must continually innovate in order to succeed over time. In recent decades, an increasing portion of this innovation is enabled or driven by digital technologies. New products, services, operations, business models, industrial arrangements, work organization, etc., have all been dramatically influenced by the digital technologies that are involved in their development, and the digital technologies that are embedded in the innovations themselves.

The goal of this minitrack is to offer a venue for research that focuses on digital innovation, broadly defined. This includes research into unique and specific effects of digital technologies on different forms of organizational innovation. In particular, new business models, forms of service offerings, products, or ways of organizing processes that did not exist before the availability of large scale digitalization.

Along these lines, we have identified four broad themes in associated with digital innovation:

\section{(1) New Business Models and Digital Innovation} Widespread digital capabilities and associated practices are enabling a variety of new business models. Topics such as digital disruption of traditional industries, digital transformation of existing organizations, and digital convergence of technologies and ecosystems are all at the forefront of new business models.

\section{(2) Digital Technologies and Process Innovation}

Advancements in digital technologies have made possible new ways of doing things within and among organizations. These new ways of doing things take the form of process innovations that have the potential to transform those organizational contexts.

\section{(3) Digital Technologies and Product / Service} Innovation

Digital technologies can also be a key component of novel product and service offerings. These technologies can have a tremendous impact organizational structure and strategy, as recent work on digital architectures, modularity, platforms, and systems integration have discovered.

\section{(4) Infrastructures and Platforms of Digital Innovation}

The digital technologies, tools, platforms, and infrastructures that support innovative processes such as software development, product design \& engineering, R\&D, and science are becoming ubiquitous. Such innovative organizational practices may be different than other organizational practices because they involve virtual collaboration, geographic distribution, iteration, simulation, and other generative activities. The tools and infrastructures upon which these practices rest might shape those practices in different industrial contexts.

This minitrack explicitly emphasizes the way in which particular forms of digital technologies contribute to organizational innovation in a variety of ways. Papers in this minitrack carefully attend to the fundamental elements and features of the digital technologies that shape or impact innovation processes and outcomes. 